Document downloaded from:

http://hdl.handle.net/10251/79921

This paper must be cited as:

Tormos Martínez, BV.; Olmeda González, PC.; Gomez Estrada, YA.; Galar, D. (2013). Monitoring and analysing oil condition to generate maintenance savings: a case study in a CNG engine powered urban transport fleet. Insight - Non-Destructive Testing \&amp; Condition Monitoring. 55(2):84-87. doi:10.1784/insi.2012.55.2.84.

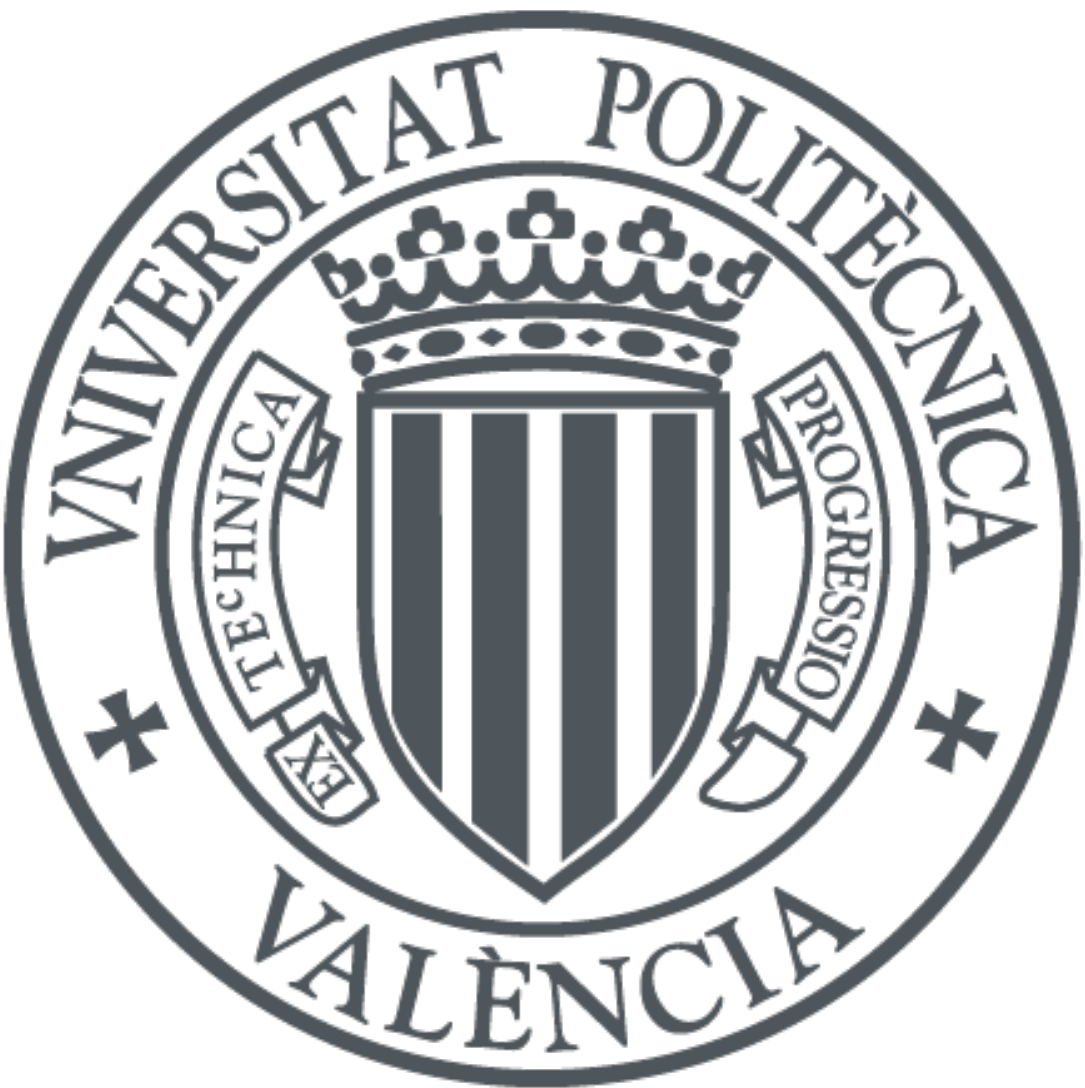

The final publication is available at

http://dx.doi.org/10.1784/insi.2012.55.2.84

Copyright British Institute of Non-destructive Testing

Additional Information 


\section{Monitoring and analysing oil condition to generate maintenance savings: a case study in a CNG engine powered urban transport fleet.}

\section{Introduction}

The longest time interval (base) in Preventive Maintenance (PM) for automotive applications is the period between engine oil changes; this, along with other planned maintenance tasks is usually referred to in multiples or submultiples of this base period, although tasks related with safety aspects are considered separate to this general rule. The minimum requirements and characteristics for the lubricants used and the period between oil changes are usually defined by the engine or vehicle manufacturer (OEM). This base period takes different factors into account, such as the potential service type (heavy or light), fuel type, etc., with OEMs usually trying to define a period that assures maximum reliability and minimum risk, an especially important factor when the warranty period is also considered.

It is common practice in transport fleets (automotive, railways, etc.) to use oil analysis programs to calculate the optimal time interval between oil changes, always trying to maximise the useful life period of the engine oil ${ }^{(1)}$. Taking this into account, the frequency of other planned maintenance tasks related to this base period might also be reduced. This would result in savings not only from using fewer parts (used oil or oil filters etc.), but also the reduced workload, decreased shutdowns and services, and less frequent residue disposal which, combined, could dwarf the savings made on parts alone.

The use of Compressed Natural Gas (CNG) engines for automotive applications has significantly increased in recent years in Europe and the US, and furthermore is an important sector in South Asian countries ${ }^{(2)}$. Predictions for this sector are very good in Europe and the US, largely as a result of the technology's typical advantages: lower emissions, lower noise levels, and energy source diversification. Urban transport fleets, including those for public transport and garbage collection are optimal candidates for this type of technology.

Considering that $\mathrm{CNG}$ engines for automotive applications is an emerging market in Europe, some specifics of this technology should be considered. Firstly, these engine types require a specific end-user fuel delivery infrastructure, thus incurring additional costs. Manufacturers commonly offer similar vehicles powered by either CNG engines or Diesel engines, thus the preventive maintenance program should be very similar for each, especially when considering that differences in frequency may be considered as another economic disadvantage against $\mathrm{CNG}$ engines. Thus, it is quite common that the oil change interval is the same for both the technologies offered by a specific manufacturer.

However, the CNG engine combustion process requires the engine oil to support a higher level of thermal stress compared with similar Diesel engines ${ }^{(3,4)}$ and as a consequence either higher quality engine oils must be used in CNG engines or shorter oil drain intervals have to be applied. Both these solutions can be interpreted as a competitive disadvantage of this technology because of the higher maintenance costs from using more expensive oil, or a larger quantity of oil over time.

This case study used a real urban transport fleet, that uses both Diesel and CNG powered vehicles, to quantify the differences in the engine oil degradation rate for both types of engine, and to assess how different cost or quality engine oils behave in CNG vehicles. This study presents data arguing that, taking a global economic overview, it is more appropriate and profitable to use higher quality and more expensive engine oil in CNG engines than the minimum quality engine oil defined by manufacturer. 


\section{Experimental Set Up}

The work was divided into two different parts, first a comparative assessment of engine oil behaviour between Diesel and CNG engine powered vehicles was performed, showing that demands on CNG engine oils are higher than in Diesel engines, as highlighted by a faster oil degradation rate in the former. The Second part was a comparative study of two different quality engine oil formulations in order to assess their behaviour. Finally, a simple economic study was performed to evaluate the costs and potential savings for each combination.

\subsection{Fleet Data and Oil Analysis Program}

\section{Vehicle Selection}

An urban transport fleet company kindly agreed to collaborate with us on this research; they are involved in public transportation in a medium-large city. Two different vehicle types were considered in this study: CNG and Diesel engine powered vehicles, and were used to define the reference baseline. These engines must support severe urban engine cycles, with constant 'stop and go', long periods of engine idling, and a typical average commercial speed of $12.7 \mathrm{~km} / \mathrm{h}$. Vehicles were operated for 16 hours a day in two eight-hour shifts. Drivers and routes were assigned randomly. Vehicle age ranged from 2 to 6 years old. The city in which this test was carried out is very level, with few gradients, and differences between the route lengths is negligible, so no selection bias was considered. The main engine characteristics are presented in Table 1.

\begin{tabular}{|c|c|c|}
\hline Characteristics & CNG engine & Diesel engine \\
\hline Type & Indirect Injection / Turbocharged & Direct Injection / Turbocharged \\
\hline Number of vehicles involved & 12 & 4 \\
\hline Number of Cylinder & 6 & 6 \\
\hline Bore / stroke $(\mathrm{mm})$ & $115 / 125$ & $128 / 155$ \\
\hline Engine displacement (cc) & 7,790 & 11,967 \\
\hline Power $(\mathrm{kW})$ & $200 @ 2,000 \mathrm{rpm}$ & 220@1,900 rpm \\
\hline bmep (bar) & 15.4 & 11.6 \\
\hline Power/displacement $(\mathrm{kW} / \mathrm{l})$ & 25.67 & 18.38 \\
\hline $\begin{array}{l}\text { Oil drain period }(\mathrm{km}) \text {. Engine } \\
\text { manufacturer recommendation }\end{array}$ & 30,000 & 30,000 \\
\hline Oil sump capacity (1) & 23 & 31 \\
\hline OSF (Oil Stress Factor) $\left(\mathrm{kW} \cdot \mathrm{km} / \mathrm{l}^{2}\right)$ & 33487 & 17790 \\
\hline Oil type in use & Oil A / B & Oil C \\
\hline
\end{tabular}

Table 1. Main engine characteristics.

\section{Sampling Program and Procedures.}

The study was done over a 6 month period in which more than 190 samples were collected and analyzed. Used oil samples were taken for analysis every 2,000 km for CNG engines and 5,000 km for Diesel engines. Samples were also taken at each scheduled oil change at $15,000 \mathrm{~km}$ or $30,000 \mathrm{~km}$ for $\mathrm{CNG}$ engines, and $30,000 \mathrm{~km}$ for Diesel engines, according to the operator policy. The different time intervals between oil changes in CNG engines are related to the quality of engine oil used, and are discussed below. All of the samples collected were representative, and cross-contamination was carefully avoided.

The main fresh oil characteristics of two different gas engine oils (referred to as oil A and B), which correspond to differently formulated, different quality CNG engine oils, along 
with Diesel engine oil (oil C), are presented in Table 2. All engine oils fulfilled the minimum requirements for each type of engine considered, as defined by the engine manufacturers.

\begin{tabular}{|l|c|c|c|}
\hline \multicolumn{1}{|c|}{ Characteristics } & Oil A & Oil B & Oil C \\
\hline SAE Grade & $10 \mathrm{~W} / 40$ & $15 \mathrm{~W} / 40$ & $15 \mathrm{~W} / 40$ \\
\hline Density at $15^{\circ} \mathrm{C}\left(\mathrm{kg} / \mathrm{m}^{3}\right)$ & 865 & 885 & 881 \\
\hline Viscosity at $40^{\circ} \mathrm{C}(\mathrm{cSt})$ & 91.8 & 112.0 & 108.0 \\
\hline Viscosity at $100^{\circ} \mathrm{C}(\mathrm{cSt})$ & 14.3 & 14.5 & 14.5 \\
\hline Viscosity index & $160 \mathrm{~min}$. & $125 \mathrm{~min}$. & $130 \mathrm{~min}$. \\
\hline T.B.N. $(\mathrm{mg} \mathrm{KOH} / \mathrm{g})$ & 13.2 & 10 & 10 \\
\hline Flash point, open cup $\left({ }^{\circ} \mathrm{C}\right)$ & $>220$ & $215 \mathrm{~min}$. & $215 \mathrm{~min}$. \\
\hline Pour point $\left({ }^{\circ} \mathrm{C}\right)$ & $<-33$ & -27 & $-27 \mathrm{max}$ \\
\hline Sulphated Ash $(\% \mathrm{wt})$ & $<1.0$ & 0.95 & - \\
\hline Specifications & API CI-4, ACEA & \multirow{2}{*}{ API CF-4 } & $\begin{array}{c}\text { ACEA E7/E5, API } \\
\text { CI-4/CH-4/SL }\end{array}$ \\
\hline
\end{tabular}

Table 2. Main fresh oil characteristics.

\section{Oil Analysis Program Performed}

Oxidation and nitration measurements were performed using an A2T Technologies FT-IR spectrometer with a standard Zinc Selenide (ZnSe) beam splitter a $100 \mu \mathrm{m}$ path length, maximum spectral resolution of $4 \mathrm{~cm}^{-1}$, and a spectral range from 4000 to $650 \mathrm{~cm}^{-1}$.

Oxidation tests were carried out according to the standard ASTM D 7214-07 ${ }^{(5)}$ protocol, and the oxidation level was determined in the spectral range between 1660 and 1820 $\mathrm{cm}^{-1}$, using Peak Area Increase methodology with a single baseline. The result is reported as PAI (Peak Area Increase): the carbonyl region area multiplied by the dilution factor (in this case no dilution was required) and divided by the cell path length $(100 \mu \mathrm{m})$. The same methodology was used to measure nitration, using a spectral range between 1650 and 1600 $\mathrm{cm}^{-1}$.

Total Acid Number (TAN) and Total Base Number (TBN) were measured using automatic potentiometric titration equipment (ORION 950 Ross FASTQC Titrator). The titration solutions used in this study were those established as standards (ASTM D 664 and ASTM D 2896). These measurements can be considered as a good estimator of oil condition by reflecting the depletion of additives in the oil, acidic contamination, and oxidation level.

The Remaining Useful Life or RUL number was measured using RULER ${ }^{\circledR}$ equipment (FLUITEC) using blue solution vials. This device is based on linear sweep voltammetric techniques ${ }^{(6,7)}$.

\section{Results and Discussion}

The changes in the RUL time period are presented in Figure 1. As shown, there was more rapid additive consumption in samples from $\mathrm{CNG}$ engines (oils $\mathrm{A}$ and $\mathrm{B}$ ) compared with slower consumption in Diesel engines (oil C). Additionally, the two oils used in CNG engines behaved differently; additives were very quickly depleted in the lower quality oil B, leading to a reduction in the time required between oil changes compared to that recommended by the manufacturer, normally at $15,000 \mathrm{~km}$. On the other hand, oil A was still of sufficient quality to exceed the manufacturer's recommended time between oil changes, at $30,000 \mathrm{~km}$, and at this point still maintained a RUL of approximately $35-40 \%$, usually considered sufficient to run engines with no damage. 
As observed, the degradation rate was higher in $\mathrm{CNG}$ engine oils as a consequence of the higher thermal stress put on those oils ${ }^{(8)}$, important when comparing the similar quality oils $\mathrm{A}$ and $\mathrm{C}$, taking the differences between both engine types, presented in Table 1, into account.

The change in oxidation and nitration levels can be observed in Figures 2 and 3. We would like to highlight two main features: on one hand, as expected for CNG engine oil type $\mathrm{B}$, the oxidation rate per mile is clearly higher than for engine oil type $\mathrm{A}$, which is related to oil quality (mainly related with the types and concentration of antioxidants added); on the other hand, the oxidation levels reached in the Diesel engine oil (type C) were lower than the values reached for $\mathrm{CNG}$ engine oil type $\mathrm{A}$, as a consequence of the lower thermal operation requirements for Diesel engine oil. In all cases, nitration results show a clear correlation with the oxidation results, as expected.

Figure 4, shows the changes in the TBN and TAN from samples from both engine types and with different engine oils (to improve clarity not all individual data (dots) are depicted on this graph). Considering that the point at which TBN and TAN meet on the graph is considered the optimal oil change time, the data displayed indicate that the recommended time between oil changes for oil type B has been perfectly defined. Similarly, oil type A performed well, reaching the $30,000 \mathrm{~km}$ oil change interval time, as expected. Interestingly, these data indicate that the possibility of applying a longer oil drain interval for Diesel engines using oil $\mathrm{C}$ should be studied.

\section{Economic Analysis}

Focussing only on CNG engines, selecting the best oil for them is based on an economic analysis, bearing in mind not only the lubricant price but also the benefits of a longer oil change time interval. The different costs taken into account in this economic analysis are related only to the oil draining maintenance process and not to those associated with other maintenance actions that would normally be performed at the same time, given that this base time interval is the period to which other maintenance actions are usually planned. These costs are:

- Lubricant cost $(1.69 € / 1$ for oil $\mathrm{B}$ and $5.1 € / 1$ for oil $A$, i.e. 3 times more expensive for oil A).

- Filter cost (11.33€/unit in both cases).

- Oil residue disposal $(0.0504 € / 1$ in both cases).

- Filter residue disposal (0.0375 €/unit in both cases).

- The immobilized time (134 $€ / \mathrm{h}$ in both cases).

- Personnel workload costs (0.68 hours has been estimated for each change, with a cost of $35 € / h)$.

- Oil refills required over time have been measured yielding values of 0.24 1/1000 km (oil B) and 0.19 1/1000 km (oil A).

- In both cases the oil pan volume is 231 and the oil change interval is 15,000 and $30,000 \mathrm{~km}$ for oils $\mathrm{A}$ and $\mathrm{B}$ respectively. We have assumed that each vehicle covers about $37,000 \mathrm{~km} /$ year.

Figure 5 shows the different costs for both types of oil, per vehicle, per year, and in both cases the immobilized time is almost the biggest cost, suggesting that the longer the oil change period the lower the cost. As expected, the difference in the cost of the oils is also relevant: as shown in Figure 5, using the more expensive oil A, an economic saving of 88 
$€ /$ year per vehicle is expected, or in other words $23.8 € / 10,000 \mathrm{~km}$, corresponding to a $21 \%$ saving.

\section{Conclusions}

Considering that the engine oils used in $\mathrm{CNG}$ engines require higher performance characteristics due to the higher stress suffered by those engines, it has been shown that proper engine oil selection for these types of 'real service' engines can be translated into economic savings if the oil purchase cost and the related maintenance costs are both considered.

Applying an accurate and well defined oil analysis program can help save a large amount of money by detecting and avoiding incipient failures and their subsequent related costs, and furthermore by helping us to select the most appropriate oil for each application.

An economic analysis should be performed to assure maximum potential benefits, and should not consider only purchase costs; it should go deeper to consider other related factors such as the maintenance costs derived from oil changes.

\section{Acknowledgements}

The authors from Universitat Politècnica de València wish to thank to Spanish Grant TRA2008-06508 from Ministerio de Ciencia e Innovación - Dirección General de Investigación for supporting this work. Mr. Gómez thanks to the UPV his grant 2011-S2-5003 in the frame of the PAID program.

\section{References}

1. V Macián, B Tormos, P Olmeda, L Montoro and E Anubla, "Results and benefits of an oil analysis programme for railway locomotive Diesel engines", Insight, 45, pp. 402-406, 2003.

2. NGVA - Natural and bio Gas Vehicle Association Europe. Worldwide NGV Statistics. http://www.ngvaeurope.eu/worldwide-ngv-statistics.

3. A R Semin and A B Rosli, "Combustion Temperature Effect of Diesel Engine Convert to Compressed Natural Gas Engine", American Journal of Engineering and Applied Sciences, 2, pp. 212-216, 2009.

4. E Adril, S Abdullah, A Ariffin, A Muchtar and K Omar, "Comparative Study of Characteristic of Lubricant Oils in Gasoline and Compressed Natural Gas Engines". European Journal of Scientific Research, 30, pp 282-293, 2009.

5. D7214-07 (2007), "Standard Test Method for Determination of the Oxidation of Used Lubricants by FT-IR Using Peak Area Increase Calculation. ASTM International, West Conshohocken, PA.

6. R E Kauffman and W E Rhine, "Development of a remaining useful life of a lubricant evaluation technique, part-I, differential scanning calorimetric techniques", Lubrication Engineering, Vol. 44, pp. 154-161, 1998. 
7. R E Kauffman, "Remaining useful life measurements of diesel engine oils, hydraulic fluids and greases using cyclic voltammetric methods", Lubrication Engineering, Vol. 51, pp. 223-229, 1994.

8. V Macián, B Tormos, J M Salavert, and Y A Gómez. "Comparative Study of Engine Oil Performance on CNG/Diesel Engines on an Urban Transport Fleet", SAE Paper 2010-01-2100, SAE 2010 Powertrains, Fuels \& Lubricants Meeting, October 2010.

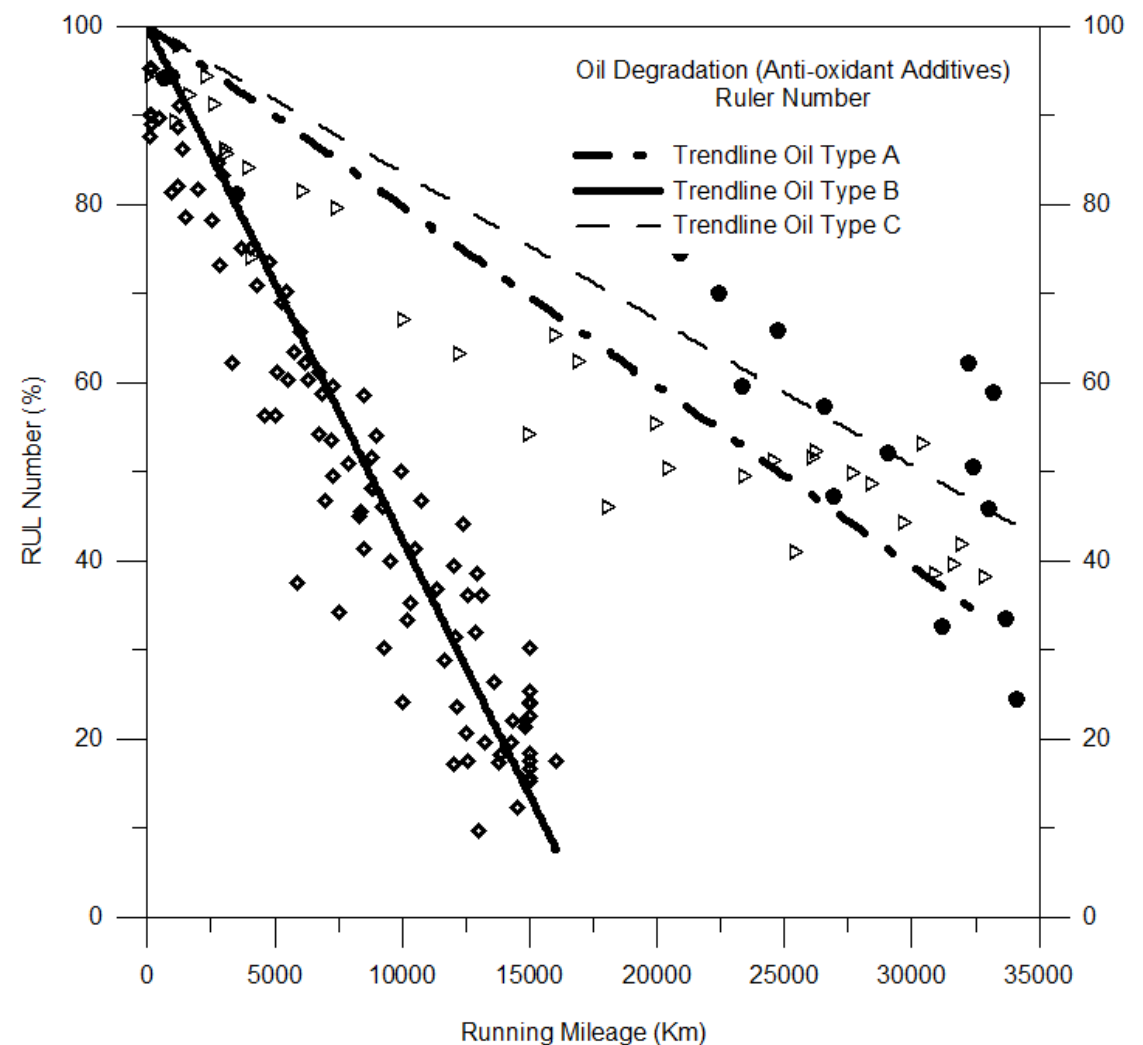

Figure 1. RUL number evolution for all oils during the test.

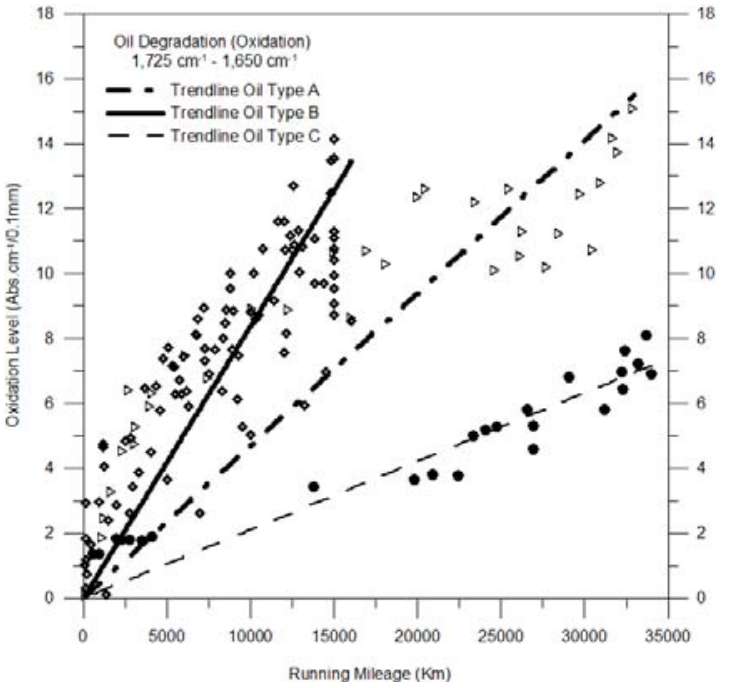

Fig. 2: Oxidation measurements evolution for all oils

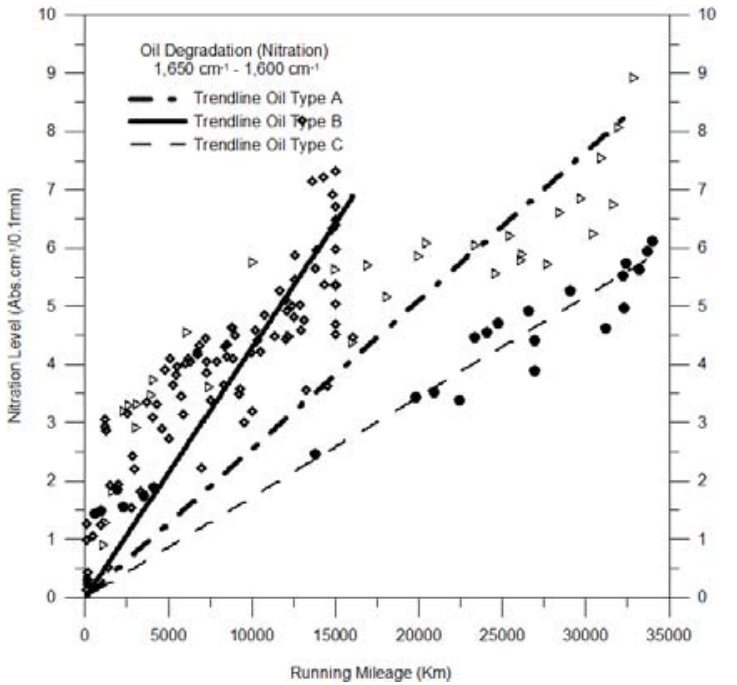

Fig. 3: Nitration measurements evolution for all oils 


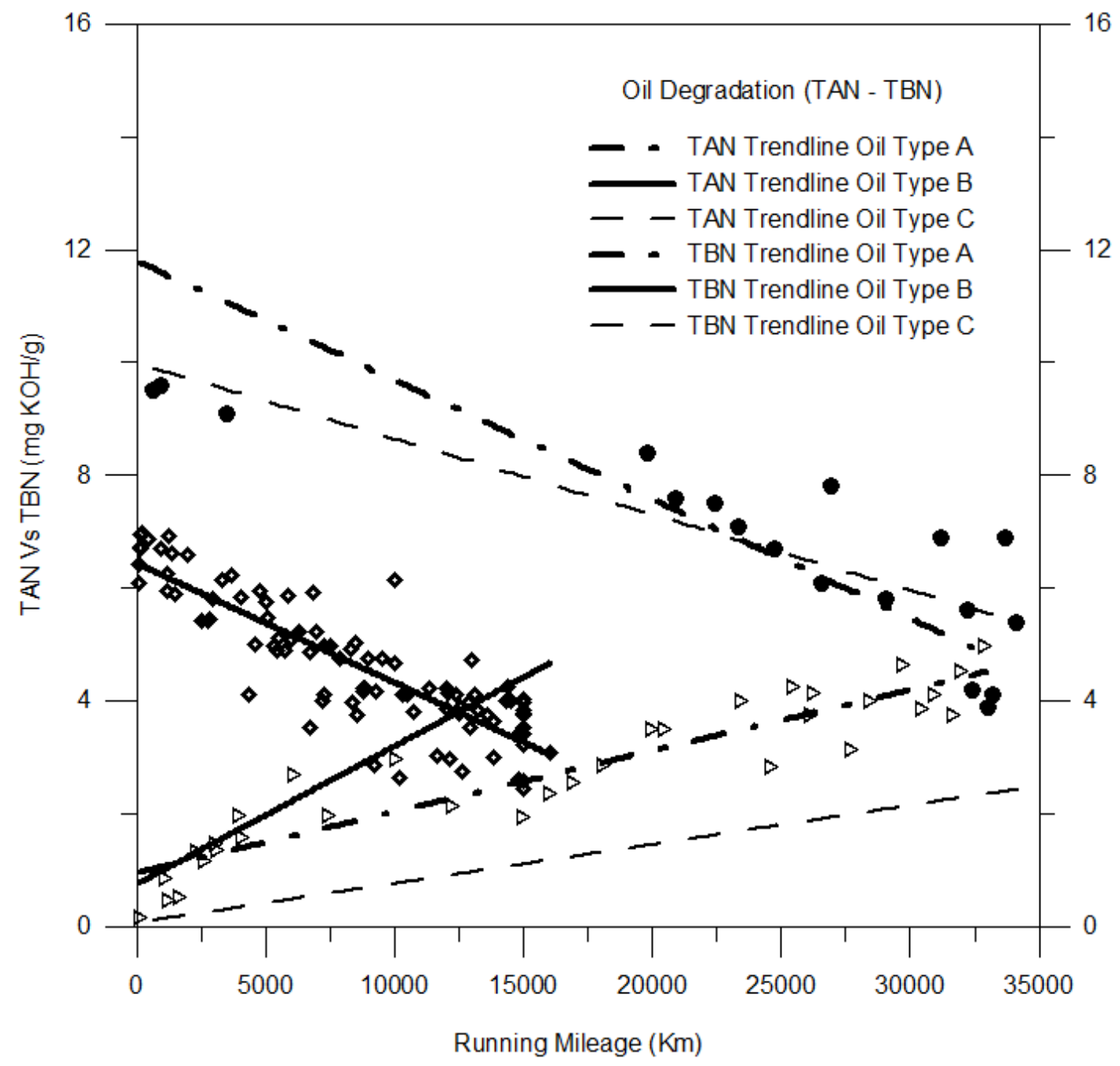

Figure 4. TBN and TAN trend lines for all engine oils.

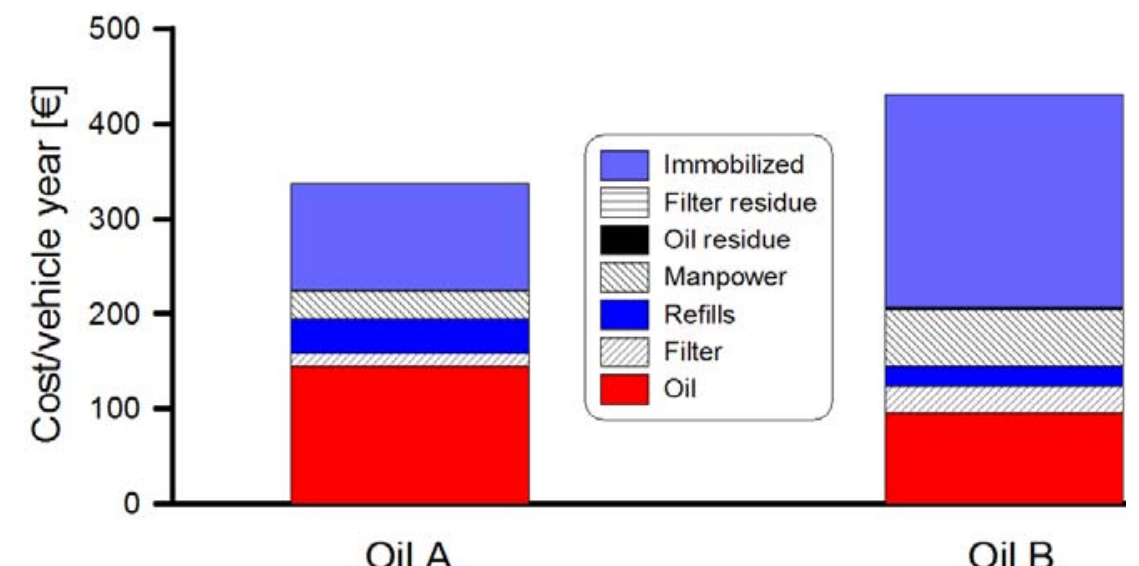

Figure 5: Cumulative costs per vehicle and year for both types of oils. 